\title{
The Comparison of Chinese and English Idioms ---from the Perspective of Ethics
}

\author{
You Wang ${ }^{1,2}$ \\ 1. Research Center for Language and Language Education, \\ Central China Normal University, \\ Wuhan, P.R. China, postcode:430079 \\ 401784689@qq.com \\ 2 . School of Foreign Languages, Jianghan University, \\ Wuhan, P.R. China, postcode: 430056
}

Keywords: Ethics; Chinese Idioms; English Idioms; Language comparison

\begin{abstract}
There are huge differences between Chinese and English people's understanding of Ethics, which is reflected in languages, especially in idioms. Chinese ethics is based on the thoughts of "Nature-Human Integration" and "Collectivism", while the English ethics is obedient to the thoughts of

"Nature-Human Separation" and "Individualism". This essay compares and analyzes the reflection of Chinese and English ethics in Chinese and English idioms.
\end{abstract}

\section{Chinese and English Ethics}

Every nation's culture is a complex integrity, which includes many aspects of the social life. Language, as the important part of human society, is the carrier of culture, as well as the reflection of the nation's world views, personal values, and ethical moral values. The ethical moral values are not only the foundation of a nation based on which it survives and develops; they are also the core contents of a nation's culture.

Chinese Dictionary defines the term "Ethics" as: human relations and moral principles, referring to the moral criterion of people's getting along with each other. In the Chinese culture, ethics is the principle to handle the relationship among human beings and their relationship with the nature. For example: five nature ethics "heaven, earth, emperor, kinship, teacher"; five human ethics "emperor and official, father and son, brothers, couple, friends". The five rules to handle the human ethics are: loyalty, filial piety, respecting brothers, forbearing, and honesty. The definition of "Morality" is: one of the social ideologies, the standards and specifications of people's life and behavior.

The definition of ethics in English is apparently different from the Chinese one. The definition of Ethics in The Concise Oxford Dictionary (10th edition) is: 1. the moral principles governing or influencing conduct. 2. the branch of knowledge concerned with moral principles. And the definition of Morality is: 1. principles concerning the distinction between right and wrong or good and bad behavior: a system of values and moral principles. 2. The extent to which an action is right or wrong.

From the above definitions we can see that in English, both Ethics and Morality do not include the contents of human relationships., it's not difficult for us to find, from the different definitions of "ethics" in these two languages, that there is huge differences on the ethics conceptions between China and the West. Although English nation's ethics doesn't refer to nature-human or human-human relationship, the contrastive research in this essay takes Chinese ethics as the object, and it will be done from the English nation perspective on the relationship between nature and human, as well as human and human.

"Nature-Human Integration" Theory and "Nature-Human Separation" Theory

The nature and human theory is the foundation of Chinese ethics, which is relationship between nature and human beings. There are huge differences between Chinese and English nations on the relationship 
of human and nature. China advocates nature-human integration, while Britain advocates nature-human separation. This is related to the different geographical locations, economic conditions and historical culture backgrounds of the two countries.

Chinese advocates "Nature-Human Integration". Human and nature should be harmonious. The trace can be tracked from Chinese ancient myths, like: "Pan Gu creats the heaven", "Nv Wa mends the sky", "Hou Yi shoots nine suns". The relationship between China and nature is very close. Chinese Han nation's origin is in the Yellow River basin, basically an inland country, with agricultural economy based on natural economy. Our ancestors work with the sunrise, relax with the sunset in the vast land, they observe the earth, birds, beasts and other creatures, get inspirations from observing human bodies and the universe. They "understand the virtue of the gods, feel the compassions for everything". People in this kind of world generate the sense of stability and harmony.

The theory of "Nature-Human Integration" was actually formed in the Qin and Han dynasties[1]. Zhongshu Dong, in the West Han period, put forward the idea of "Nature-Human Integration": "The common sense of heaven and earth is "yin" and "yang". "Yang" refers to the nature's virtue; "yin" refers to the nature's punishment..... The nature also has its own joy and anger, sad and happiness, which fit the human beings, thus nature and human are an integration". He also said, "Everything follows the name, all the names follow the nature. Nature and human are integration. Although it is Zhongshu Dong first put forward the idea of "Nature-Human Integration", he did not use the exact words. It is Zai Zhang in Song dynasty who first applied this term. He claimed "the Confucians are honest because of wisdom, wisdom because of honesty, therefore, nature-human Integration". The nature of Chinese culture can be explained as "uniting nature and human, uniting inside and outside". "Nature-Human Integration" represents the harmony of natural rules and human ethics.

"Nature-Human Integration" is also the foundation of Han Nation's ethical morality, which shapes the thinking mode and value orientation of the people who speak Chinese, guides these people to seek for the harmony and unity of human and nature, human and society, as well as human and human. There are many Chinese idioms that reflect the thought of "Nature-Human Integration". Chinese people pursuit "good time is inferior to good position, good position is inferior to human harmony" [2].

Some Chinese idioms that advocate human and nature are interlinked

\begin{tabular}{|c|c|}
\hline Yi mai xiang tong & Ren yuan tian nu \\
\hline Tian lun zhi le & Tian yu ren gui \\
\hline Tian ren zhi ji & Tian ren gong jian \\
\hline
\end{tabular}

Some Chinese idioms that affirm the power of nature

\begin{tabular}{|c|l|}
\hline Tian bu zuo mei & Tian bu jia nian \\
\hline Tian ren lu ge & Tian zuo zhi he \\
\hline Tian ren zhi ji & tian zhu di mie \\
\hline
\end{tabular}

The idioms that tell people to obey the nature

\begin{tabular}{|c|c|}
\hline Le tian zhi ming & Shun qi zi ran \\
\hline Bi zao tian qian & Tian luo di wang \\
\hline Ren suan bu ru tian suan & Ren zai zuo, tian zai kan \\
\hline
\end{tabular}

Western thought are different from Chinese one on the relationship between human and nature, which advocate nature and human are separated [3]. They have strong desire of controlling and conquering nature, and believe that nature and human are absolutely opposite. Most European countries, near the ocean, are lack of resources compared with continental countries; therefore people are born to overcome various limitations of adverse natural conditions, to constantly struggle with the sea. The western culture encourages people to constantly explore and develop the outside of the ocean. This 
formed not only the commodity economy on the basis of industry and commerce, but also the culture of conquering and dominating the nature. Western people also believe that people can dominate and change the nature through efforts, and in the relationship between human and nature, it is always human that is in the position of domination. So the English culture which is based on the western thoughts is seeking for changes and adventures, emphasizing the thought that nature and human are separated, material and spirit are opposite. They pay attention to the outwards conquering and expansion of space [3]. There are many English idioms that reflect the opposition between nature and human. For example:

The idioms that reflect the opposition between nature and human

\begin{tabular}{|l|l|}
\hline Nature, red in tooth and claw. & $\begin{array}{l}\text { Everyone is the architects of his own } \\
\text { fortune. }\end{array}$ \\
\hline $\begin{array}{l}\text { Every man is the master of his own } \\
\text { fortune. }\end{array}$ & Man will conquer nature. \\
\hline Man is the measure of all things. & Every man for himself. \\
\hline
\end{tabular}

\section{"Collectivism" VS "Individualism"}

The "Nature-Human Integration" is the foundation of ethical morality, while the "value theory" is the core contents of the ethical morality. The value theory states the relationship between individual and the others, the individual and the entirety, and how do the individuals accomplish self-value through some ethical moral ways. Chinese people tend to choose the collectivism, while the western people emphasize on the individualism. This is related closely to the differences between Chinese and western culture's views on the relationships between nature and human [4].

Chinese Han culture pursues harmony and unity under the influence of the thought of "NatureHuman Integration", which believes that nature, human and society can not be separated. They are interdependent, as an organic whole. One basic value of Chinese traditional ethics is to attach importance to entirety and neglect individuality. Chinese ancient people, limited by natural conditions, have fairly small activity surroundings. The social structure at that time is that home and country are united---one's home is the microcosm of a country, and the country is an enlarged home [5]. The idea "Nature-Human Integration" makes Chinese people believe that human is a part of nature, human's things are natural fate, and human ethics is natural rules. Ethics, humanity, popularity should be one. The kinship is the most important relationship between humans, and the origin of all the other relationships. There's almost no "individual" space for individuals in these group relationships. The idea that believes human, nature and society are one entirety leads to Chinese Han culture's thinking mode of attaching importance to the entirety, and it also leads Chinese people's ethical value view of group and collectivism. This ethical thought believes that the realization of human's value must depend on the collectivity; if one separates from the others and the society, the individual value will not exist. It also advocates to the whole, and attach importance to country [6]. There are many Chinese idioms that reflect the ethical value view of collectivism, like:

\begin{tabular}{|c|c|}
\hline Yi bu nan zhi & Zhong zhi cheng chen \\
\hline Du li nan zhi & Qun ce qun li \\
\hline Jing zhong bao guo & An guo nin jia \\
\hline
\end{tabular}

Of course the thought that affirms the group power may lead to the idea of neglecting individuals, emphasizing the individual's complete obeisance to the group, and avoiding self-expression. Here come the following Chinese idioms: 


\begin{tabular}{|c|c|}
\hline Tao guang yang hui & Shu da zhao feng \\
\hline Chen mo shi jin & Bu lu feng mang \\
\hline Qiang da chu tou niao & Zhen ren bu lu xiang \\
\hline
\end{tabular}

The "Nature-Human Separation" thought influenced the English nations. The basic concept of western ethical value is to advocate individualism and ego [7]. In the 6th century B.C., Athens emphasized the cities' interest as well as the individual's roles. The western nation's manufacturing methods are mainly sailing, which decides that they can not live together for a long time, and the kinship is relevantly loose. During the social changes, those regional countries replaced kinship nations, individualisms replaced the clan standards. In the "individualism" ethics, each individual's social role is not family member but citizen; the relationship between people is not ethical one with blood button, but the one under the country's political systems. In this culture, if an individual wants to accomplish his value, he must be different, independent, and expressive. Therefore this kind of western ethical value is considered to be "emphasizing on individuals" [8]. The English nation's ethical value is based on the western "individualism" [9]. Different from Chinese individualism, which means selfish and harm the others' interest, in English culture, individualism is the necessary condition to accomplish self-value [10]. In their eyes, Chinese culture's following the trends means losing personality. There are idioms that reflect English nation's ethical morality of individualism.

\begin{tabular}{|l|l|}
\hline God help those who help themselves. & Modest dog miss much meat. \\
\hline The squeaky wheel gets the grease. & Everyone for himself and God for us all. \\
\hline To thy own self be true. & Self comes first. \\
\hline $\begin{array}{l}\text { A man is called selfish, not pursuing his } \\
\text { own good, but neglecting his neighbour's. }\end{array}$ & \\
\hline
\end{tabular}

\section{Conclusion}

The core of Chinese ethics is the relationship within humans and between human and nature; English ethics discusses the moral standards that dominate or influence the behaviors, i.e. the standard of right and wrong. Since the definitions of ethics are different, the understandings are different. The differences are reflected in languages especially in idioms. This essay compares and analyzes the reflection of Chinese "Nature-Human Integration" and English "Nature-Human Separation" theories, as well as the reflection of "collectivism" and "individualism" in Chinese and English idioms.

\section{References}

[1] Youlan Feng: A Brief History of Chinese Philosophy, Beijing: Beijing University Press, 1985

[2] Haiping Liu: The Contrastive Analysis on Chinese Collectivism and English individualism, Journal of Lanzhou (2009) 8

[3] Zhenxi Luo: The Influence of Chinese and Western Thoughts on Chinese and English Languages, Journal of East Forestry College (2004) 12 [4]. Jizhong Shi: The Differences of Chinese and Western Philosophy, Guizhou Social Science, (1993) 5

[5] Ailin Zhang, Aiwen Zhang: On the Differences between English and Chinese Thinking Pattern, Journal of Chongqing University (2002) 5

[6] Ruolan Zhang: The Characteristics and the Cultural Differences between English and Chinese Idioms, Journal of Xi'an Foreign Languages College (2003) 6 
[7] Bobrow, S. \& Bell, S: On Catching on to Idiomatic Expressions. Memory and Cognition (1973) 1

[8] C. Cacciari, P. Tabossi: The comprehension of idioms. Journal of Memory and Cognitive (1988) 27

[9] C. Fernando, R. Flavell: On idioms. Exeter: University of Exeter, 1981

[10] C. Kramsch: Language and Culture. Shanghai: Shanghai Education Press, 2000 